\title{
AN RFID ADOPTION FRAMEWORK: A CONTAINER SUPPLY CHAIN ANALYSIS
}

\author{
Lisa F Seymour, Emma Lambert-Porter and Lars Willuweit \\ Information Systems Department \\ University of Cape Town, ZA
}

\begin{abstract}
While the benefits of RFID (radio frequency identification) in supply chains have had extensive press, publicised cases showing poor returns on investment and a relative lack of research into its adoption has left organisations feeling uncertain about the challenges to be managed when assessing RFID adoption. This qualitative study in the South African port community refines and extends an RFID adoption framework and provides insight into the factors potentially affecting the adoption of this new technology as well as the probability of adoption in that community. Four new factors not previously mentioned in research were identified: related initiatives; the integrated structure of the industry; organisational dominance with the supply chain and the supply chain culture. An argument for their validity within the RFID adoption framework is presented. The research reveals that cost, the absence of a universally-adopted standard and the supply chain culture are currently the major setbacks to RFID adoption in the South African port community.
\end{abstract}

Keywords: RFID, Container Supply Chain, technology adoption

\section{Introduction}

The increasingly competitive nature of global markets has forced supply chain organisations to increase collaboration and flexibility in their business processes. Yet, the extended integration of a large number of parties along global supply chains means that a number of inefficiencies such as delayed shipments, shrinkage and billing delays can be incurred at many points. The solution to these inefficiencies is deemed to be complete tracking of goods in a cost-effective manner (Nikam and Satpute 2006). Radio Frequency Identification (RFID) has been proposed as a tracking solution due to its ability to enhance efficiency and quality of information exchange. Yet, many companies have failed to achieve benefits from RFID adoption and a relative lack of research on RFID adoption has left organisations feeling uncertain about the challenges to be faced (Ranganathan and Jha 2005). This calls for research to address unresolved RFID adoption issues.

Therefore, the main objective of this research was to understand and identify factors potentially affecting RFID adoption through refining and extending the RFID adoption framework proposed by Seymour et al. (2007). We chose to analyse the South African (SA) port community perceptions on (RFID) adoption

Please use the following format when citing this chapter:

Seymour, L.F., Lambert-Porter, E. and Willuweit, L., 2008, in IFIP International Federation for Information Processing, Volume 274; Advances in Information Systems Research, Education and Practice; David Avison, George M. Kasper, Barbara Pernici, Isabel Ramos, Dewald Roode; (Boston: Springer), pp. 175-188. 
within the container supply chain. Ports play a fundamental part in global trade and global supply chains. As increasing trade pressures put their throughput under pressure, they are turning to technology solutions. Jansen (2005) argues that there are drawbacks in many development frameworks as they do not allow for specific national contexts and priorities. Each nation has its unique geography, history and culture and research needs to take into consideration these specifics. A second objective was therefore to understand the context of RFID adoption within the SA container supply chain and obtain insight into the probability of adoption.

\section{RFID and other supply chain technologies}

For RFID to yield supply chain visibility, it needs to be integrated with other supply chain technologies (SCTs). SCTs assist organisations with tracking and are classified as either informational; decision oriented, or transactional (Singh et al. 2007). Transactional systems include enterprise resource planning (ERP) systems and decision oriented systems include Advanced planning systems (APS) found in APS packages and in the supply chain management components of ERP systems. Informational technologies include Extranets, EDI and RFID. The three types of SCTs are integrated to enable tracking. RFID tags are placed on items which then pass through the reader's generated magnetic field, identifying the item. The information is communicated, filtered by middleware and transferred typically via an integration server to the transactional and decision-oriented systems.

\section{Factors influencing RFID adoption}

Organisations need a systematic framework to assess the fit of new technologies with their organisation and to understand adoption implications. Bakry (2003) proposed the STOPE model which can assist in determining the readiness of organisations to adopt new technologies. The model introduces five basic elements of development used in e-readiness analyses: Strategy (with regards to the future development of the industry), Technology (upon which the industry is based), Organisations (related to the industry), People (concerned in the industry) and Environment (existing in the industry). With intra- and inter-organizational factors included, the model provides a comprehensive base for technology adoption across multiple organisations. Using this model as a lens Seymour et al. (2007) reviewed the literature and identified factors relevant to RFID adoption. Their framework was used in this study.

\section{Methodology and Data Collection}

This study was, in essence, 'open-ended' with the goal of explaining factors, considering the influence of context on perceptions, and determining whether or not factors were relevant. For these reasons we used a qualitative approach which allowed for a deeper understanding of the themes influencing adoption and for the emergence of new themes. The research was conducted by interviewing nine members of the Cape Town port community (It1 to It9) during July 2006. We en- 
deavoured to interview a full spread of representative organisations, but accept that the results would have been improved if interviews had been conducted with the likes of customs, trucking companies and individual exporters and importers but the range of interviews still provided useful results. The interviewees are detailed in Table 1 without interview codes so as to ensure their anonymity. To obtain a good understanding of the situation, we conducted semi-structured interviews, consisting of both set and open-ended questions. We used an electronic recording application and hand-written notes to record the interviews and full transcripts were produced. We edited the data to ensure that no omissions had been made and that the data was consistent and then coded the data by placing the interview responses into themes and categories, before being analysed for frequency to establish patterns in the given responses. As part of the literature review, data collection and during analysis we needed to gain an understanding of the context of the SA container supply chain into which the RFID technology could be deployed. The following section details the context.

Table 1. Organisations and job positions of the nine interviewees.

\begin{tabular}{|l|l|}
\hline Container Terminal Marketing Manager & Shipping line Operations Manager \\
\hline Container Terminal Operations Manager & Shipping line Logistics Manager \\
\hline SA Port Operations IT Manager & Shipping line IT Manager \\
\hline Container Depot e-Commerce Manager & An RFID Vendor and Expert \\
\hline Shipping line Systems Administrator & - \\
\hline
\end{tabular}

\section{The South African Port Community}

The SA (SA) port community consists of a number of integrated parties, namely the importers/exporters, container depots, customs, container terminals and shipping lines. All operations are governed and influenced by two Transnet subsidiaries, the SA Port Operations (SAPO) and the National Port Authority which both replaced Portnet in 2000. In 1990, Transnet changed from being government run to a public company with government as its only shareholder. The National Port Authority is responsible for regulations and policy formations, and SAPO provides operational services such as cargo-handling and logistics to the port community. Customs, a division of the SA Revenue Service (SARS), inspect and collect import duties on incoming containers and check that they meet government and legal regulations (It3). Spoornet, Transnet's freight rail division also influences the container supply chain.

The central purpose of the ports is to berth container vessels, and load or unload them. Container terminals also offer container storage for a limited amount of time (It1). In South Africa, all container terminals are government-owned and controlled (It1). Container depots are privately-owned and provide their customers (importers and exporters) with the service of container storage. Container depots that are registered with customs also offer their clients container packing and unpacking services (It7). The shipping lines are privately-owned, are run locally 
through agencies and transport containers for a service fee, own the containers and administer and manage the vessels and containers (It3). Shipping lines would be the direct implementers of RFID technology as it would be their duty to install RFID tags into the containers.

Information is passed between parties at various points. When exporting goods, exporters send a shipping instruction to the shipping line which then creates the manifest (a complete list of the containers on board and the contents thereof) and then the bill of loading. The shipping line gives the depot an instruction to release an empty container (It6). The manifest is sent physically with the vessel to the destination port and/or electronically before the ship departs (It6). In the case of exports to the US, the local port must send the electronic manifest and expected arrival time to the destination port at least 24 hours before the vessel departs (It6). To dispatch a container from a port, the shipping line needs to issue a container terminal order to the trucking company which can then collect the container.

\section{Analysis and Interpretation}

In this section, we analysed the interviews according to the themes in the framework and new factors that were identified were incorporated into the relevant STOPE categories. These themes are contrasted with the literature and their implications to the SA container supply chain are discussed. As this is a short paper, the analysis of some themes which were not that relevant to the South African context was not included.

\subsection{Strategy: Organisational strategies}

If an organisation's strategy is to increase value or service quality, then this strategy acts indirectly as an enabler for adopting RFID. In this study strategies were both enablers and obstacles to adoption, with Governmental strategies dominating the supply chain. While global competitiveness and increased security are government strategies which enable adoption, the social responsibility to create jobs, a factor more dominant in developing countries was seen as an obstacle to adoption. It 2 noted that while the mission of Transnet is to reduce the cost of business, they have a social responsibility to alleviate unemployment. The fit with employment strategies was not clear. While It2 stated with certainty that RFID might "kill jobs", It4 commented that "RFID creates higher level employment". A further obstacle appeared to be the strategy of shipping lines which was seen as merely following technological innovations proposed by other parties as opposed to being innovative.

\subsection{Strategy: Related initiatives}

While not mentioned in the literature, we found "related initiatives" to be a factor influencing RFID adoption. Three of the seven organisations interviewed referred 
to a recent initiative of Spoornet to move containers onto rail to relieve truck congestion on the roads. They stated that RFID would help to track containers on the railways and therefore would enable the move to rail (It9, It8 and It1). The benefits of RFID would complement the Spoornet initiative and therefore this initiative is indirectly an enabler to RFID adoption.

\subsection{Technology: Cost / Resources}

As if and Mandviwalla (2005) found cost to be a significant challenge to the adoption of RFID and this study found cost to be one of the most significant factors. All interviewees commented on cost and the high cost of infrastructure, information integration and the tags were all cited. It7 argued that equipping containers with RFID would not cost-effective unless a 'critical mass', of between 50 and 60 percent of the containers that pass to and from South Africa, were installed with tags. There was acknowledgment that all port community members needed to bear a portion of the total cost (It6, It7, It8). However, the probability of this when the benefits are realised in varying degrees by each member was seen as small. For instance, trucking companies would see great benefit in reducing the amount of time taken to enter and leave a port or depot (It4, It7, It8). However because they operate on low margins and compete only on price, benefits might not outweigh the costs (It6, It7, It8). For the shipping lines, it was felt that because the manual, nonautomated work (that would be replaced with RFID) is shouldered by other parties in the port community, the reduction in shipping costs and human errors would probably not justify the investment (It8, It3). Interestingly, only one respondent referred to cost savings and the value added through efficiency and throughput gains. Hence perceived value needs to be considered in conjunction with cost.

\subsection{Technology: Perceived value / Usefulness}

The literature implies that all organisations within a supply chain stand to gain benefits from adopting RFID. The majority of respondents cited benefits. The tracking capabilities of the technology was seen as the core potential benefit, which is in line with the motivation for the RFID project in line the Rotterdam port (RFid Gazette 2005). The stated major benefit of RFID was knowing where a container is and when it entered the gate, was loaded onto a ship etc. (It4, It5, It6, It7, It8). Tracking would therefore improve planning and document flow (It6) and information sharing (It1, It2). The port community had "about ten separate systems", and RFID would help with "the gap of information between the port and the depot" (It3).

Some respondents referred to increased throughput and efficiency. "Tight [shipping line] deadlines might be a huge enabler for RFID” (It3). "Ports are very poor in terms of throughput... for example a trucker is standing in line for four hours to move a container from a port to a depot" (It7). "There is always a shortage of space... the quicker you can get containers out of your system, the better" (It6). Reduction in manual labour was also commented on. "It would really benefit 
[the container depots] to reduce some of the work in entering and exiting facilities" (It7). "The industry is very paper-based, people work 18-20 hours a day to meet manifest deadline" (It3). The value of RFID also seemed to be increasing in this area. "Global trade is increasing in excess of $10 \%$ per annum, you either have to employ more people or get the existing people to work more." "Manual input is increasing every year" (It6). Temperature control was also identified as a potential benefit (It8). RFID tags with encoding options allow for the monitoring of temperature, reducing spoilage (Ryzex Group 2005).

The organisations interviewed that considered RFID to be of great benefit/value to their organisation were more willing to consider it. As an observation there is a perception that other organisations might benefit from RFID and therefore it appears that benefits to their own organisations is not understood or that there is little understanding that individual benefits are only accrued with integrated implementation and community-wide efficiency gains. It1 and It2 both repeated that the container terminal would not really gain any benefits from RFID as it was only part of the supply chain. It 4 and It5 stated that shipping lines would gain no competitive advantage from RFID because "all the manual work is done by other parties throughout the port community", and that the port authorities, truckers and depots would benefit more. The port operations also felt RFID was of little benefit to them (It8).

\subsection{Technology: Complexity/Ease of use}

Most (4 of the 7) organisations had concern over the complexity of RFID information and business processes. Concerns were raised on the amount of information. "You would need information from all customers for all cargo types within a container on the chip" (It7). A container is manufactured in Japan and "then it moves to America, South Africa, West Africa, South America and Europe" (It4). The tag needs to be scanned and updated upon import, leaving the port and on arrival at the customer and the reverse upon departure (It6). Three of the organisations referred specifically to the complexity of the technology implementation (configuring business rules) and not the technology itself. This obstacle is not that easily overcome, because of the global nature of the problem and the poor infrastructure of a number of members in the port community.

\subsection{Technology: Accuracy}

Many (4 of the 7) organisations interviewed felt that accuracy was a consideration. It4 and It6 noted that RFID might help reduce data entry errors. "When it's dark, when it's foggy, when it's rainy, the [manually recorded] information is sometimes incorrect" (It6). It7 spoke confidently of the RFID solution to difficulties in reading documents, mentioning that cases existed where containers had been stored on incorrect shipping lines and had been sent to, for instance, China when it should have served the American trade. In contrast to previous research by $\mathrm{Wu}$ 
et al. (2006), no organisation expressed concern that RFID might not be fully accurate, stressing instead its improved accuracy over current methods.

\subsection{Technology: Infrastructure}

Existing 'inflexible' IT infrastructure, that cannot easily be integrated with the RFID technology) has been cited to be an unavoidable challenge. In the SA port community the existence and lack of infrastructure was seen as an enabler and an obstacle respectively. The existence of EDI and other information sharing projects between SA port community members was seen as a strong enabler for adopting RFID; as such infrastructure would complement RFID use and ensure automation along the supply chain. In contrast It3 stated that some depots still have paperbased processes. It7 noted that "many of the smaller importers and exporters don't even have PCs". Therefore the state of infrastructure is seen as both an enabler and an obstacle.

\subsection{Intra-Organisation: Training and support}

Training and support has been cited as enablers for user adoption. However, these factors are not seen to be relevant in early adoption. In contrast, the amount of reskilling is seen as an obstacle to adoption. It 1 stated that manual work would have to be replaced with higher level skills and It6 mentioned that current systems are manual other than the use of hand held computers to enter seal numbers.

\subsection{Intra-Organisation: Organisation-wide readiness}

Comments were made on the readiness states of other but not their own organisations. It 8 stated that "hardly any exporter and importers have the ability to send manifests electronically". It appears that the integrated and interconnected nature of the community reduces the effect of a single organisation's readiness.

\subsection{Intra-Organisation: Organisation size}

The literature suggests that organisation size can play a significant role in technology adoption as larger organisations are generally more innovative because of extra capacity and financial resources (Patterson et al. 2003). None of the interviewees referred to the size of their respective organisation or its impact on adoption. It5 noted that the size and employment legislature of the port authority was a potential obstacle. In this research the larger organisations are seen to be government controlled with less need for innovation than privately-owned organisations.

\subsection{Inter-Organisation: Security}

In contrast to published security concerns of competitors 'stealing' information with fraudulent scanners (Smith 2005), concerns and benefits focused around current security problems and looting of containers. It2 raised the concern that 
through the RF scanning of containers, container terminal employees would be able to ascertain container contents resulting in "targeting the containers with valuables and stealing the contents". It7 mentioned that Spoornet had incidents of people getting information from their system when preparing manifests, and then following containers and looting them. In contrast to this, It1 confidently argued with authority that the number of instances where security was breached through either lost or looted containers was minimal, eradicating the need for RFID for security.

It1 noted a security-related benefit that "implementing RFID might reduce the number of people on the yard". It3 also stressed that RFID would allow reallocation of resources from data inputting to security issues. A further RFID security benefit is the availability of seals with embedded RFID chips (It9). "The integrity of the seal is very important for us as a shipping line because we are responsible that the cargo gets from A to B intact" (It6). "[RFID vendors] can guarantee the customer that goods have left, show where they are in the supply chain, and show that they haven't been tampered with" (It9). It6 noted that the US security protocols demanding manifest information 24 hours before a shipment leaves would "give RFID a push". However, It8 added confidently that RFID would not play much role in satisfying what the US wants SA to do before containers get shipped, because the requirements for the US are more around pre-screening and x-ray scanning of containers.

There was ambiguity among the interviewees over whether or not the high security requirements required by the shipping industry makes RFID a suitable solution. From a physical security and data security perspective, it appears that RFID meets the security needs of the industry in the form of accurate seal readings, reliable tamper-detection, tracking of containers and international security standards.

\subsection{Inter-Organisation: Customer needs/satisfaction}

Effective supply chain management requires that organisations strive to meet the needs of the end customer and interviews showed that customer satisfaction is still fundamentally important in the SA port community. Overwhelmingly, customer benefits were mentioned by interviewees as a positive consequence of RFID adoption. The tracking benefit was seen as significant, RFID "can guarantee the customer that the goods have left, show where they are in the supply chain and show that they haven't been tampered with" (It9). It6 noted enthusiastically that locating containers via a website would replace the lengthy, hour-long process of the customer phoning the shipping line, the shipping line phoning the depot etc. RFID could also provide "more stages where the container is scanned and tracked". It7 noted that with some tracking information currently being available to customers, "people have been seeing the holes in information, and so they put more pressure on shipping lines" who in turn had put pressure on SA port authorities, thereby implying that customer needs would indirectly drive RFID adoption. A further benefit of RFID was seen as the ability to break back into the US market. It7 said 
that the US security restrictions have meant that many exporters had been cut from US market and that enforced RFID adoption or similar "external drives would give it [US exports] a push". Speaking from personal opinion, It8 countered the more positive views by saying that "the shipping line of customers would indirectly pay for RFID" through the spill-over increase in costs.

\subsection{Inter-Organisation: Intensity of information exchange}

According to Ranganathan and Jha (2005) the information intensity and demanding nature of the container supply chain makes the possibility of RFID adoption greater. Evidence was given to show that the industry is information-intensive and the ability of RFID to bridge information gaps would enable adoption. It3 noted the number of parties were involved in the information flow, giving an example of how a container terminal order moves from shipping line to port, to trucking company, to depot and to customer. It 3 said that a lot of information is collected on manifests and other documents and only some of it electronically. It1 stressed that there were over ten separate systems and minimal [electronic] information sharing, and that connecting systems would benefit the whole community.

\subsection{Inter-Organisation: Integrated structure of industry}

While not mentioned in the literature, the interconnected nature of the container supply chain does play a large role in the adoption of RFID. During the interviews, all parties made allusions to the heavily-interconnected nature of the port community, highlighting the need for improved information sharing and buy-in from many parties. Six of the seven parties noted in some way that all parties within the port community would need to reach consensus to adopt RFID. "Everyone is interlinked; therefore no single organisation can make a decision on whether or not to implement RFID... depots, port authority, customs and shipping lines would need to meet consensus" (It4). It4 repeated very clearly, "If RFID is going to be used; everybody in the world needs to comply." "The complete supply chain would have to be taken into account. Otherwise you only get half the benefit" (It9).

\subsection{Inter-Organisation: Organisational dominance within supply chain}

A factor identified by the research and not found in previous research is organisational dominance within the supply chain and in this case it was the influence of Government on port operations. A strong majority (It1, It6, It7, It9, It5) felt that the policy of their organisation was governed by a higher body. It9 noted that decisions concerning new technology adoption were made at a national level from the "SAPO, Customs, and Department of Trade point of view". It5 alluding to government influence said that the RFID implementation in Japan would be easier because depots are owned by the shipping line, "but in South Africa, this is not the case". It5 also commented that government organisations have little experience with IT projects which contributes to their slowness to react to technologies such 
as RFID. It5 reiterated, "It is hard to change the way that people think in government monopolies, things move very slowly". The monopoly or perceived government control over the container terminal presents a number of issues. Less emphasis appears to be placed on improving competitive advantage. At the beginning of 2006 Transnet was acknowledged as being an unwieldy conglomerate (Ramos 2006) and ultimately the control over RFID adoption is seen to lie with government who is perceived as slow with change and inexperienced with IT projects. Organisational dominance within a supply chain is not unique to this case, the Wal-Mart RFID adoption could arguably be attributed to its dominance within its retail supply chain. In mid-2004 Wal-Mart required that its top suppliers attach RFID tags to all cases and pallets (Hartman 2004).

\subsection{People: Resistance to change}

A fear of change in the work environment has been reported as an obstacle to RFID adoption (Asif and Mandviwalla 2005). While interview analysis found that resistance to change was not a factor explicitly stated by interviewees, resistance by IT management to changing IT systems was a potential obstacle. Both It1 and It 2 argued that "COSMOS (the container terminal legacy system) is good enough."

\subsection{People: Expertise}

The lack of RFID expertise within the supply chain community was noted. This obstacle is not insurmountable, as expertise is available in South Africa but a cost. "There is the [necessary] intelligence in South Africa, but it comes down to funds from the industry" (It6).

\subsection{Environment: Willingness to collaborate}

The container terminal's willingness to support any RFID initiative, despite not being clear on its ability to bring benefits, implies willingness to collaborate. It7 noted with clarity that getting parties to agree to adopt RFID together is incredibly difficult as they want RFID advantages for themselves and "throw sticks and hurdles in the path of any progress". It took 7 years of discussions to reach some agreement on EDI" (It7). It was felt that without a driver from government, reaching consensus would be too slow.

\subsection{Environment: Relative advantage}

Most organisations invest in a new technology with the long-term view to obtaining a competitive advantage over competitors. In this case relative advantage is both an obstacle and enabler, because while shipping lines might view the lack of relative advantage over competitors as an obstacle, trucking companies might view the benefits as an enabler. The container terminal and port authority monopolies did not consider relative advantage a consideration in RFID adoption. 


\subsection{Environment: Standards}

A minority ( 2 of 7 ) of the interviewees mentioned standards. They spoke authoritatively on the subject and cited the lack of a single universally-accepted RFID standard as a major obstacle. "If there was a standard technology and communication standard, then [the port authority] would be more than happy to adopt RFID, as long as there is a significant percentage of containers that have RFID built into them" (It8). It7 stated that "it will be a very long process to get a standard going that's internationally accepted by all shipping lines."

\subsection{Environment: Supply chain culture}

The structure and mindset of the industry as a whole was not mentioned in the literature and yet is an overriding feature and an important obstacle for the SA port community. Interviewees commented on the overall culture of the port community implying that it was inert, made up of monopolies, bureaucratic, not serviceoriented enough and lacking initiative. It5 remarked that "the mindset in South Africa is not service-oriented enough to help with implementing RFID", implying that the overall culture of the industry is not suited to RFID adoption or process innovation. It5 compared the port authority to a monopoly and commented that it was inert, "things move so slowly, because of the red tape". It7 commented that "It would be very difficult to motivate anything like this from a SA perspective". While SAPO and the National Port Authority both replaced Portnet in 2000 and Transnet changed from being government run in 1990, some interviewees still referred to Portnet and government ownership of the Transnet subsidiaries.

\section{RFID adoption within the South African container supply chain}

The major issues surrounding the adoption of RFID into the SA port community are presented in Table 2. The high costs and complexity of the RFID technology was found to be partially offset by the improved accuracy and usefulness of the technology. The Infrastructural and integration costs are high requiring all players to shoulder the cost. The complexity of the technology is overshadowed by complexity of the implementation; a challenge made harder by the poor infrastructure of a number of members involved in the port community. While benefits to the overall supply chain were not well understood, improved throughput; productivity; tracking; information sharing and temperature monitoring were identified. In terms of strategy, the lack of innovation and social responsibility to increase jobs is offset by global competitiveness, increased security requirements and enabling the more environmental move from truck to rail transport. Inter-organisational factors were found to enable adoption, but these are partially offset by intraorganisational factors. The good fit of RFID for customer needs in terms of tracking benefits and the potential to enable US exports as well as the security benefits of accurate seal readings, reliable tamper-detection, tracking of containers, international security standards and reduction of manual work are all seen to enable adoption. The obstacles include the size and employment legislature of the port 
authority and the substantial re-skilling required. People factors did not appear to have a strong impact while environmental factors presented as obstacles. The multiple standards for RFID hardware, software, and data management are seen as seen as a major obstacle and interviewees implied that the port community culture was inert, made up of monopolies, bureaucratic, not service-oriented enough and lacking initiative.

Table 2. Categories and Themes Identified for the Assessment of RFID Adoption. New themes are indicated in bold.

\begin{tabular}{|c|c|c|}
\hline Categories & Themes & SA case \\
\hline \multirow[t]{2}{*}{ Strategy } & Organisational strategies & \\
\hline & Related initiatives & Enabler \\
\hline \multirow{5}{*}{ Technology } & Cost / Resources & Obstacle \\
\hline & Perceived value / Usefulness & Enabler \\
\hline & Complexity / Ease of use & Obstacle \\
\hline & Accuracy & Enabler \\
\hline & Infrastructure & \\
\hline \multirow{4}{*}{$\begin{array}{l}\text { Intra- } \\
\text { Organisation }\end{array}$} & Organisation culture & \\
\hline & Training and support & Obstacle \\
\hline & Organisation-wide readiness & \\
\hline & Organisation size & Obstacle \\
\hline \multirow{5}{*}{$\begin{array}{l}\text { Inter- } \\
\text { Organisation }\end{array}$} & Security & Enabler \\
\hline & Customer needs / satisfaction & Enabler \\
\hline & Intensity of information exchange & Enabler \\
\hline & Integrated structure of industry & \\
\hline & Organisational dominance within supply chain & \\
\hline \multirow{3}{*}{ People } & Management support / Authority & \\
\hline & Resistance to change & \\
\hline & Expertise & \\
\hline \multirow{4}{*}{ Environment } & Willingness to collaborate & \\
\hline & Relative advantage & \\
\hline & Standards & Obstacle \\
\hline & Supply chain culture & Obstacle \\
\hline
\end{tabular}

\section{Conclusion}

Through a thorough qualitative assessment of the intricacies of the Cape Town port community, we have highlighted and discussed the major issues surrounding the adoption of RFID into the SA port community. In addition to this, a framework for the adoption of the technology, presented as the structure of Table 2, has been refined. The four themes revealed through interview analysis and not identified by the literature review are presented in bold. These factors could present themselves as either enablers or obstacles. The right hand column in Table 2 identifies factors we found to influence RFID adoption in the SA container supply 
chain. Overall, cost, the absence of a universally-adopted standard and the supply chain culture were revealed to be the major setbacks to RFID adoption in the port community. The bureaucratic and monopolistic nature of the supply chain community contributes to the creation of an environment that struggles to reach a position of consensus. These are partially offset by customer needs and usefulness. Other uniquely South African elaborations on factors were revealed, including the idea that South Africa is not 'service-oriented' enough. An interesting finding which needs future research.

\section{References}

Asif, Z., Mandviwalla, M. (2005). Integrating the Supply chain with RFID: A technical and business analysis, Communications of the Association for Information Systems, 15, 393-427.

Bakry, S. H. (2003). Toward the development of a standard e-readiness assessment policy, International Journal of Network Management,13(2), 129-137.

Hartman, L. R. (2004). Walmart's on schedule with RFID revolution. Retrieved from http://www.packagingdigest.com/articles/200407/36.php.

Jansen, A. (2005). Assessing E-government progress- why and what, Proceedings of NOKOBIT 2005. Retrieved from http://www.afin.uio.no/forskning/ notater/7_05.pdf. Accessed 3 March 2008.

Nikam, M., Satpute, S. (2006). RFID: Changing the face of supply chain management, (Working Paper, Welingkar Institute of Management and Development Research). Retrieved from http://www.indiainfoline.com/content/bschool/ Your_Journal/2006/05/30052006/Chan.pdf. Accessed 12 June 2007.

Patterson, K. A., Grimm, C. M., Corsi, T. M. (2003). Adopting new technologies for Supply Chain Management, Research Part E: Logistics and Transportation Review, 39(2), 95-121.

Ramos, M. (2006). Group Chief Executive's review. Retrieved from http://www.transnet.co.za/AR_2006/cor_groupCE.html. Accessed 16 July 2007.

Ranganathan, C., Jha, S. (2005). Adoption of RFID Technology: An exploratory examination from supplier's perspective, Proceedings of the Eleventh Americas Conference on Information Systems, August, Omaha. Retrieved from http://aisel.isworld.org/proceedings/amcis/2005/. Accessed 11 June 2007.

The Ryzex Group. (2005). Guide to Understanding and Evaluating RFID: An Application White Paper. Retrieved from http://www.rfidjournal.com/ whitepapers/1/2. Accessed 3 April 2006.

Seymour, L., Lambert-Porter, E., Willuweit, L. (2007). RFID Adoption into the Container Supply Chain: Proposing a framework. Proceedings of the ISOneWorld Conference, April 2007, Las Vegas. ISBN: 0-9772107-6-6. Retrieved from http://www.information-quarterly.org/ISOWProc/2007ISOWCD/PDFs/55.pdf.

Singh, N., Lai, K., Cheng, T. (2007). Intra-Organizational Perspectives on ITEnabled Supply Chains: Aligning technology decisions with relevant organizational practices and policies. Communications of the ACM, 50(1), $59-65$. 
Smith, A.D. (2005). Exploring radio frequency identification technology and its impact on business systems, Information Management and Computer Security, 13(1), 16-28.

Wu, N.C., Nystrom, M.A., Lin T. R., Yu, H.C. (2006). Challenges to global RFID adoption, Technovation, 26(12) 1317-1323. 